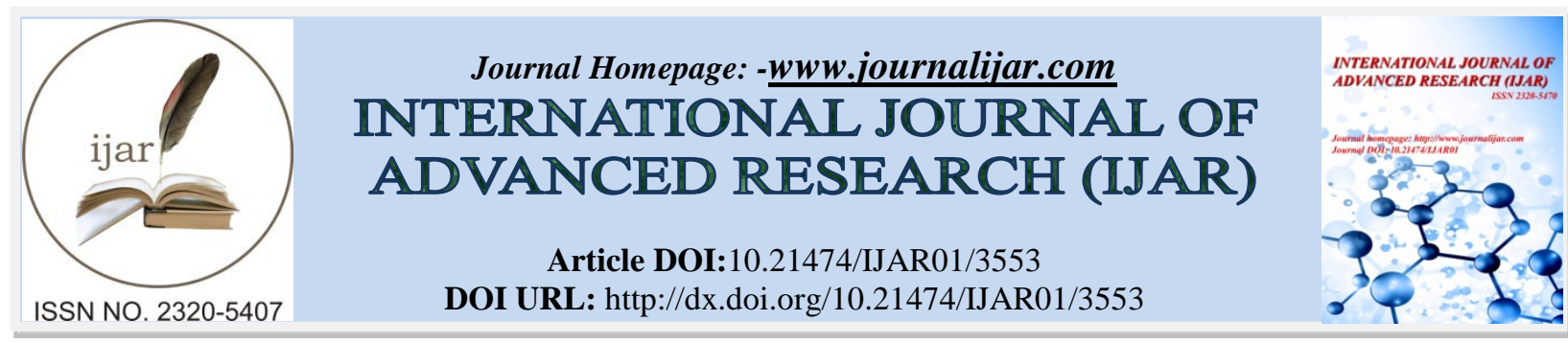

RESEARCH ARTICLE

\title{
AHP AND FUZZY TOPSIS METHODS FOR GREEN SUPPLIER SELECTION AND EVALUATION.
}

*Adnan Sarwar' ${ }^{1}$ Jiuping Xu' ${ }^{1}$, Ziqiang Zeng ${ }^{2,1}$ and Muhammad Hashim ${ }^{3}$.

1. Uncertainty Decision-Making Laboratory, Sichuan University, Chengdu, 610064, People's Republic of China.

2. Department of Civil and Environmental Engineering, University of Washington, Seattle, WA 98195, USA.

National Textile University, Faisalabad, Pakistan.

\section{Manuscript Info}

Manuscript History

Received: 01 January 2017

Final Accepted: 02 February 2017

Published: March 2017

Key words:-

green supply chain, green supplier selection, AHP, fuzzy TOPSIS.

\begin{abstract}
With the increasing awareness of environment protection, green production is one of the most important issue for every company. Green supplier selection is an essential operational function to establish sustainable partnership and improve supply chains performance. Supplier selection can be considered an essential component of green supply chain management because of its core effects. A performance measurement system is necessary to determine green supplier's ability to collaborate with industry. While the research on conventional supplier evaluation and selection is abundant but considering environmental issues are limited. This study aims to establish hybrid method for green supplier selection and evaluation. In this paper, suppliers' performance is evaluated based on both economic and environmental criterion such as cost, quality, service, green product, pollution control, and environment management.
\end{abstract}

Copy Right, IJAR, 2017,. All rights reserved.

\section{Introduction:-}

Supply chain management (SCM) aspires to increase organization's profitability, customer satisfaction, and minimize cost of product through well designed planning and control strategies. The strategic goals of SCM involve minimize supply chain costs, increase overall productivity, reduce inventory, shorten cycle time, deliver performance and enhance profitability through customer satisfaction and market share.

Nowadays, the awareness of environmental issues are forcing both public and private sector to take into account environmental aspects in their supply chains. This consideration in supply chain is called green supply chain. Green supply chain management is extension of SCM. The green supply chain management (GSCM) is recognized as environmental innovation. The concept of GSCM is stated that to incorporate environmental aspects in supply chain management. The objective of green supply chain is to minimize wastages such as energy resources, pollution, emission, and wastage along with supply chain including raw material resourcing, product design, manufacturing process, delivery of product (Rao, 2006). The green system helps to improve supply chain and production processes according to regulations of environment. Green supply chain differs from traditional supply chain. This philosophy plays important role to enhance efficiency and synergy between businesses partners, facilitate environmental performance, waste reduction, and it also help to improve ecological performance of firms and their partners (Thoo Ai Chin et al, 2015). The GSCM procedure includes planning, procurement, manufacturing, consumption, and reserve logistics.

Corresponding Author:-Adnan Sarwar.

Address:-Uncertainty Decision-Making Laboratory, Sichuan University, Chengdu, 610064, People’s

Republic of China. 
In business environment, purchasing becomes critical activity that plays important role to ensure profitability and survival of organization. The purchasing becomes more complex when environmental protection issues are taken into account because green purchasing consider supplier's environmental responsibility. Conventionally, suppliers were evaluated against conventional criterion such as price, quality, delivery lead time, flexibility, supplier's financial position, historical performance of supplier, and capacity. Recently, the consideration of environmental issues become more important in purchasing. The concept of environment in purchasing is recognized as green purchasing or green procurement. Optimal supplier selection is one of the most complex task of purchasing department. Supplier selection is one of the most critical problem facing organization where raw material and components constitute significant percentage of product cost. Green supplier selection is complicated and multicriteria decision making problems that consider both quantitative and qualitative criterion. Supplier selection problem becomes more complicated when unpredictable and uncontrollable criterion appeared due to uncertainty. In 1960s, first paper published on supplier selection. A comprehensive review on supplier selection provided by various researchers (C. A. Weber et al, 1991) ;(Ghodsypour \& O'Brien, 1998). Some popular method were applied in supplier selection process includes mathematical, categorical, artificial intelligence, and statistical methods. Due to environmental protection issues, companies prefer to buy goods and services from those suppliers that enable to provide them at low price, high quality, shorten delivery lead time, and at same time with environment protection responsibility (Amy. Lee et al, 2009).

Literature on supplier evaluation and selection is plentiful but the work related green supplier evaluation and selection is rather limited. A green vendor rating system was developed for assessment of green supplier. Supplier environmental performance was evaluated against four various environmental categories: current environmental efficiency, supplier's green image, green competencies, and net life cycle cost by utilizing AHP (Noci, 1997). Fuzzy AHP method was implemented for green supplier evaluation. The supplier was evaluated based on both conventional and environmental criteria such as price, quality, environmental competencies, environmental management system, and green image. Fuzzy logic approach was applied to overcome uncertainty (R. M Grisi et al, 2010). An integrated FAHP and Delphi method was developed for high-tech industry. First, Delphi method was proposed to differentiate criteria for both conventional and green supplier. In second phase, FAHP approach used for final ranking of supplier. Totally 11 main criterion and 41 sub-criteria were utilized (He-Yau Kang et al, 2009).Selection of green supplier is a key point in recycling economy and protection of environment. A genetic algorithm method combined with AHP for green supplier selection (Yan, 2009). Green supplier selection is important part of green supply chain management. A multi-level grey entropy synthetic method was constructed for green supplier (Yuzhong \& Liyun, 2007).

\section{Problem statement:-}

Nowadays, highly competitive and dynamic environments in globalized markets are rapidly changing and customer demanding better goods and services. In order to response in uncertain environment, manufacturer needs to produce low cost, innovative, environmental friendly, and better quality product for customers that's why companies need to select optimal supplier. Selection of right supplier is important part of production and logistics management in companies. In order to develop sustainable supply chain management, there are three business challenges in new century economic, social, and environmental issues. Introduction of environmental dimension in supplier selection process is new set of trade-offs between various attributes including both quantitative and qualitative criteria. There is limited research for supplier selection along with environmental dimension. Government made new rules and regulation for companies to minimize pollution and improve environmental performance. Green production becomes more important for every organization and will determine sustainability of producer. The consideration of environmental dimension has changed buying process. It makes the purchasing becomes more complex. The environmental protection problem is critical issue for industry. To overcome this situation, green approach is considered in supplier selection process. Supplier selection problem is one of the most important task in supply chain management. Supplier selection problem is a multi-criteria decision making problem that provides framework to evaluate suppliers using tangible, intangible, and environmental criterion. Since 1960s, researchers identified various attributes and criterion that can be considered in supplier selection process. Formerly, supplier was selected based on financial measures. Later, researchers developed quantitative and qualitative factors for supplier evaluation. In optimal supplier evaluation and selection process, manufacturer need to take into account environmental criterion as well as economics criterion such as price, quality, flexibility, and lead-time.

Appropriate supplier selection is not easy task for every company. Since, various supplier may have similar performance for different attributes. In previous decades, supplier selection was based on conventional criterion. 
Currently, due to environmental protection issue, this is not enough, organizations have to incorporate green factor in supplier selection. The objective of green supplier selection is not only to gain environment compliance but also to produce green product. Green supplier selection is complicated activity for organizations. Buyers need to buy raw material, goods and services from those vendors that can fulfil environmental rules. Green supplier selection process is important operational function in order to boost up supply chain performance and sustainability. To select most appropriate green supplier, many conventional and green criteria are considered in the decision process.

\section{Methods:-}

\section{Analytical hierarchical process (AHP):-}

Analytical hierarchical process (AHP) introduced by (Saaty, 1980). It is powerful approach to solve complex problems. AHP is used to determine relative importance of criteria in multi criteria decision making problem. It makes possible to incorporate human judgment on both intangible (qualitative) and tangible (quantitative) criterion (Badri, 2001). AHP has been widely applied to solve complicated and multi criteria decision making problem. AHP method based on three steps: first step, to develop hierarchical structure of decision problem; second step,comparative analysis of alternatives and criteria; third step, finalize synthesis of priorities.

Let $C=\left\{\mathrm{c}_{j} \mid j=1,2, \ldots, n\right\}$ be set of criterion. The results of pairwise comparison of $\mathrm{n}$ criterion can be shown as $(n \times n)$ evaluation matrix A. In evaluation matrix, every element $a_{i j}(i j=1,2, \ldots ., n)$ is quotient weight of each criteria is given below;

$$
A=\left[\begin{array}{cccc}
a_{11} & a_{12} & \cdots & a_{1 n} \\
a_{21} & a_{22} & \cdots & a_{2 n} \\
\vdots & \vdots & \ddots & \vdots \\
a_{1 n} & a_{n 2} & \cdots & a_{n n}
\end{array}\right], a_{i i}=1, a_{j i}=1 / a_{i j}, a_{i j} \neq 0
$$

In the next step, matrix (A) needs to be normalized and determine relative weight of every element. The relative weights of above matrix are given by right eigenvector $(\mathrm{W})$ to compute maximum eigenvalue $\left(\lambda_{\max }\right)$ as shown below:

$$
A_{w}=\lambda_{\max } w
$$

If pairwise comparison matrix is consistent, then $\lambda_{\max }=n$. Next step is to calculate weight through normalizing rows or columns of matrix (Wang \& Yang, 2007).The consistency index (CI) can be calculated by using equation given below;

$$
C I=\left(\lambda_{\max }-n\right) /(n-1) \text {. }
$$

The last step is to compute consistency ratio. Consistency ration can be computed (CI) divided by random index (RI) is indicated;

$$
C R=C I / R I
$$

The result of (CR) should be 0.1 or less than is accepted. If (CR) result exceeds 0.1 , the evaluation procedure needs to be repeated again in order to improve consistency of matrix (Wang \& Yang, 2007).

Table 1:-Saaty nine point scale

\begin{tabular}{|lc|}
\hline Definition & intensity of importance \\
\hline Equally important & 1 \\
Moderately more important & 3 \\
Strongly more important & 5 \\
Very strongly more important & 7 \\
Extremely more important & 9 \\
Intermediate values & $2,4,6,8$ \\
\hline
\end{tabular}




\section{Fuzzy TOPSIS method:-}

Technique for order of preference by similarity to ideal situation (TOPSIS) was developed by (Hwang \& Lai, 1993). TOPSIS is a multi-criteria decision making method that is used to rank alternatives based on shortest distance from positive ideal solution and negative ideal solution. The TOPSIS method is criticized because of its inability to handle uncertainty and impression. Later, fuzzy TOPSIS method was proposed by (Chen, 2000). In fuzzy TOPSIS method decision makers use linguistic scale to overcome vagueness and uncertainty in judgment procedure. In this paper, triangular fuzzy numbers are used in fuzzy TOPSIS method. Human vagueness, subjectivity, and impreciseness can be easily handled using triangular fuzzy numbers (Chang \& Wang, 2007).

Definition1.Fuzzy set theory was proposed by (Zadeh L. , 1965). It is extension of classical notion of set. Fuzzy numbers are powerful way to describe subjectivity measurement as compare to exact value. A triangular fuzzy number $\tilde{a}$ can be explained as triplet $\left(a_{1}, a_{2}, a_{3}\right)$ as shown in fig .1

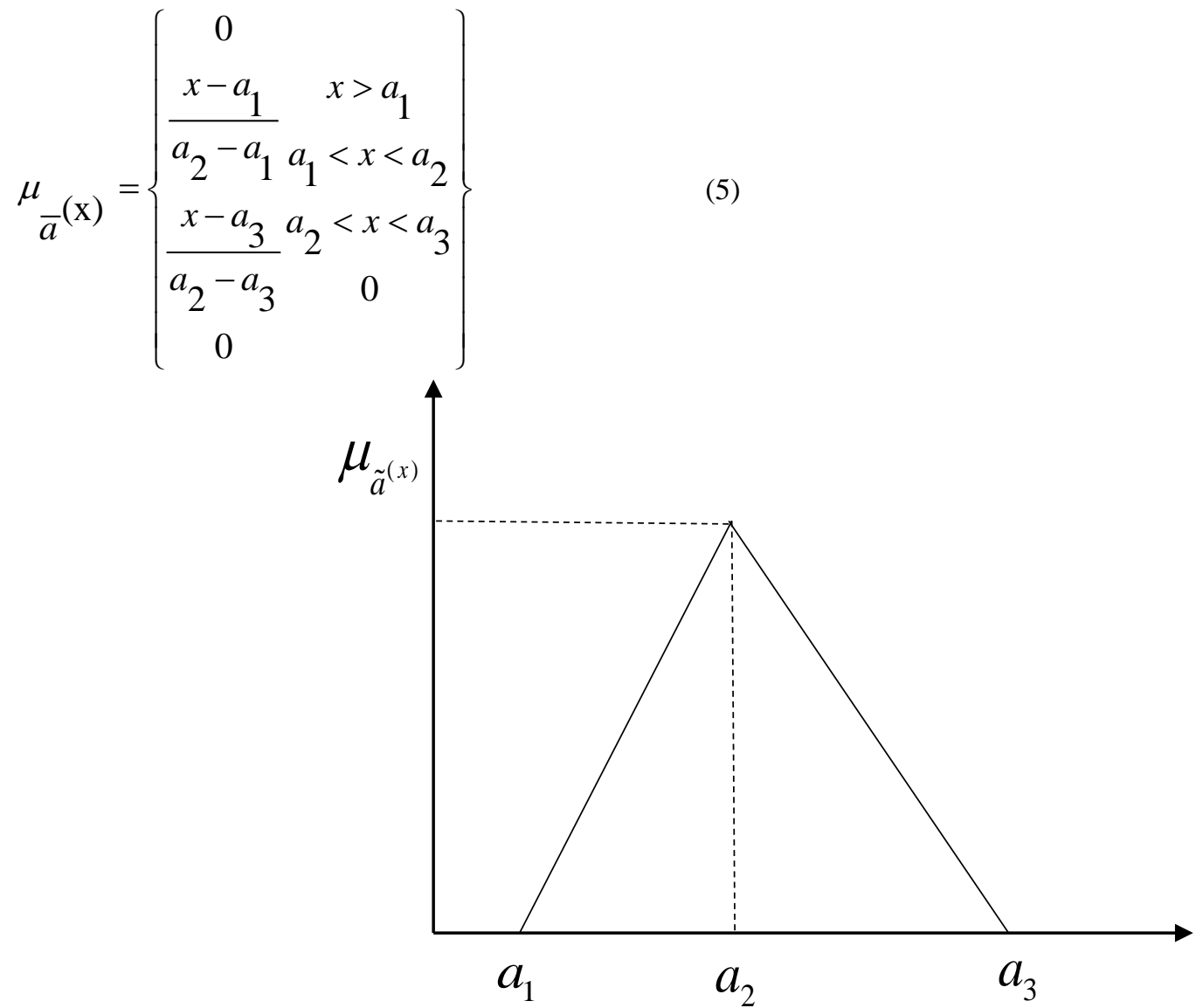

Fig. 1:- Triangular fuzzy number

Let $\tilde{a}$ and $\tilde{b}$ are two triangular fuzzy numbers. Both are parameterized by triplet $\left(a_{1}, a_{2}, a_{3}\right)$ and $\left(b_{1}, b_{2}, b_{3}\right)$. The operational laws of these two triangular fuzzy numbers is shown as

$$
\begin{aligned}
& \tilde{a}(+) \tilde{b}=\left(a_{1}, a_{2}, a_{3}\right)(+)\left(\mathrm{b}_{1}, b_{2}, b_{3}\right)=\left(a_{1}+b_{1}, a_{2}+b_{2}, a_{3}+b_{3}\right) \\
& \tilde{a}(-) \tilde{b}=\left(a_{1}, a_{2}, a_{3}\right)(-)\left(\mathrm{b}_{1}, b_{2}, b_{3}\right)=\left(a_{1}-b_{1}, a_{2}-b_{2}, a_{3}-b_{3}\right) \\
& \tilde{a}(\times) \tilde{b}=\left(a_{1}, a_{2}, a_{3}\right)(\times)\left(\mathrm{b}_{1}, b_{2}, b_{3}\right)=\left(a_{1} \times b_{1}, a_{2} \times b_{2}, a_{3} \times b_{3}\right) \\
& \tilde{a}(/) \tilde{b}=\left(a_{1}, a_{2}, a_{3}\right)(/)\left(\mathrm{b}_{1}, b_{2}, b_{3}\right)=\left(a_{1} / b_{3}, a_{2} / b_{2}, a_{3} / b_{1}\right) \\
& \tilde{a}=\left(k a_{1}, k a_{2}, k a_{3}\right)
\end{aligned}
$$


Definition 2.A linguistic variable is whose values are words or sentences in nature or artificial language(Zadeh, 1975). For instance weight is a linguistic variable; its value can be low, very low, medium, high, and very high. These linguistic terms can also be presented in the fuzzy numbers.

Let $\tilde{a}=\left(a_{1}, a_{2}, a_{3}\right)$ and $\tilde{b}=\left(b_{1}, b_{2}, b_{3}\right)$ are two triangular fuzzy numbers. In order to compute distance between them, the vertex method is defined as;

$$
d(\tilde{a}, \tilde{b})=\sqrt{\frac{1}{3}\left[\left(a_{1}-b_{1}\right)^{2}+\left(a_{2}-b_{2}\right)^{2}+\left(a_{3}-b_{3}\right)^{2}\right]}
$$

To determine different importance values of each criteria, the weighted normalized fuzzy decision matrix is constructed;

$\tilde{V}=\left[\tilde{V}_{i j}\right]_{n \times j}, i=1,2, \ldots ., n, j=1,2, \ldots . ., \mathrm{j}$,

Where

$\tilde{V}_{i j}=\tilde{x}_{i j} \times w_{i}$

A set of performance rating of $A_{j}=(j=1,2, \ldots ., j)$ with respect to criteria $C_{i}=(i=1,2, \ldots ., n)$ called $\left(\tilde{x}_{i j}\right.$, $i=1,2, \ldots, n, J=1,2, \ldots, \mathrm{J})$;

A set of performance weights each criterion $W_{i}=(i=1,2, \ldots . ., n)$.

The brief summary of above fuzzy theory and steps of fuzz TOPSIS method are described as follows (Önüt \& Soner, 2007);

Step 1: choose the linguistic values $\left(\tilde{x}_{i j}, \mathrm{i}=1,2, \ldots, \mathrm{n}, \mathrm{j}=1,2, \ldots ., \mathrm{j}\right)$ for alternatives with respect to criteria. The fuzzy linguistic rating $\left(\tilde{x}_{i j}\right)$ shows that ranges of triangular fuzzy number belong to $[0,1]$, further no need for normalization.

Step 2: compute the weight normalized fuzzy judgment matrix. The weighted normalized value $\tilde{v}_{i j}$ calculated by equation (12).

Step 3: to identify positive -ideal $\left(A^{*}\right)$ and negative -ideal $\left(A^{-}\right)$solutions. The positive ideal solution (FPIS, $A^{*}$ ) and the fuzzy negative ideal solution (FNIS, $A^{-}$) are elaborated in the following equations:

$$
\begin{aligned}
& A^{*}=\left\{\tilde{v}_{1}^{*}, \tilde{v}_{2}^{*}, \ldots, \tilde{v}_{i}^{*}\right\}=\left\{\left(\max _{j} v_{i j} \mid i \in I^{\prime}\right), \times\left(\min _{j} v_{i j} \mid i \in I^{\prime \prime}\right)\right\} \\
& \quad i=1,2, \ldots ., n, j=1,2, \ldots ., J \\
& A^{-}=\left\{\tilde{v}_{1}^{-}, \tilde{v}_{2}^{-}, \ldots, \tilde{v}_{i}^{-}\right\}=\left\{\left(\min _{j} v_{i j} \mid i \in I^{\prime}\right), \times\left(\max _{j} v_{i j} \mid i \in I^{\prime \prime}\right)\right\} \\
& i=1,2, \ldots ., n, j=1,2, \ldots ., J
\end{aligned}
$$

Where $I^{\prime}$ is associated with benefit criteria and $I^{\prime \prime}$ is associated with cost criteria.

Step 4: in order to compute the distance of each alternative from $A^{*}$ and $A^{-}$applying these equations:

$$
\begin{aligned}
& D^{*}=\sum_{j=1}^{n} d\left(\tilde{V}_{i j}, \tilde{V}_{i}^{*}\right) j=1,2, \ldots, J . \\
& D_{j}^{-}=\sum_{j=1}^{n} d\left(\tilde{V}_{i j}, \tilde{V}_{i}^{-}\right) j=1,2, \ldots, J .
\end{aligned}
$$

Step 5: last step is to determine similarities to ideal solution.

$$
C C_{j}=\frac{D_{j}^{-}}{D_{j}^{*}+D_{j}^{-}} j=1,2, \ldots, J .
$$




\section{The proposed model:-}

The AHP and fuzzy TOPSIS methods proposed for green supplier selection. The proposed model basically consists three stages: (1) formulate criterion to be used in proposed model, (2) AHP computations, (3) evaluate suppliers (alternatives) using fuzzy TOPSIS and determine final ranking of alternatives. In the first stage, suppliers and criterion that will be used for evaluation are determined and hierarchy is structured. AHP model is developed. In AHP model, objective is in first level, criterion are in second level, and suppliers (alternatives) in third level. The decision hierarchy is approved by the decision maker. After approval of hierarchical structure of decision problem, criterion used in green supplier selection are determined weights by applying AHP. At this phase, pairwise comparison of criteria are developed by using weights. The experts' team make individual evaluation by using scale given in Table 1. A final comparison matrix is formed.

In the next phase, suppliers (alternatives) ranking is determined with the application of fuzzy TOSIS method. Linguistic terms and triangular fuzzy numbers are used for evaluation of green suppliers. The membership functions of these linguistic are given in (fig. 2) and triangular fuzzy number are shown in (Table 2).

The supplier (alternative) having maximum value $C C_{j}^{*}$ is determined as the most optimal supplier according to calculation of fuzzy TOPSIS method. The ranking of other suppliers is computed according to $C C_{j}^{*}$ in descending order. The diagram of proposed model for green supplier selection is shown in Fig. 3.

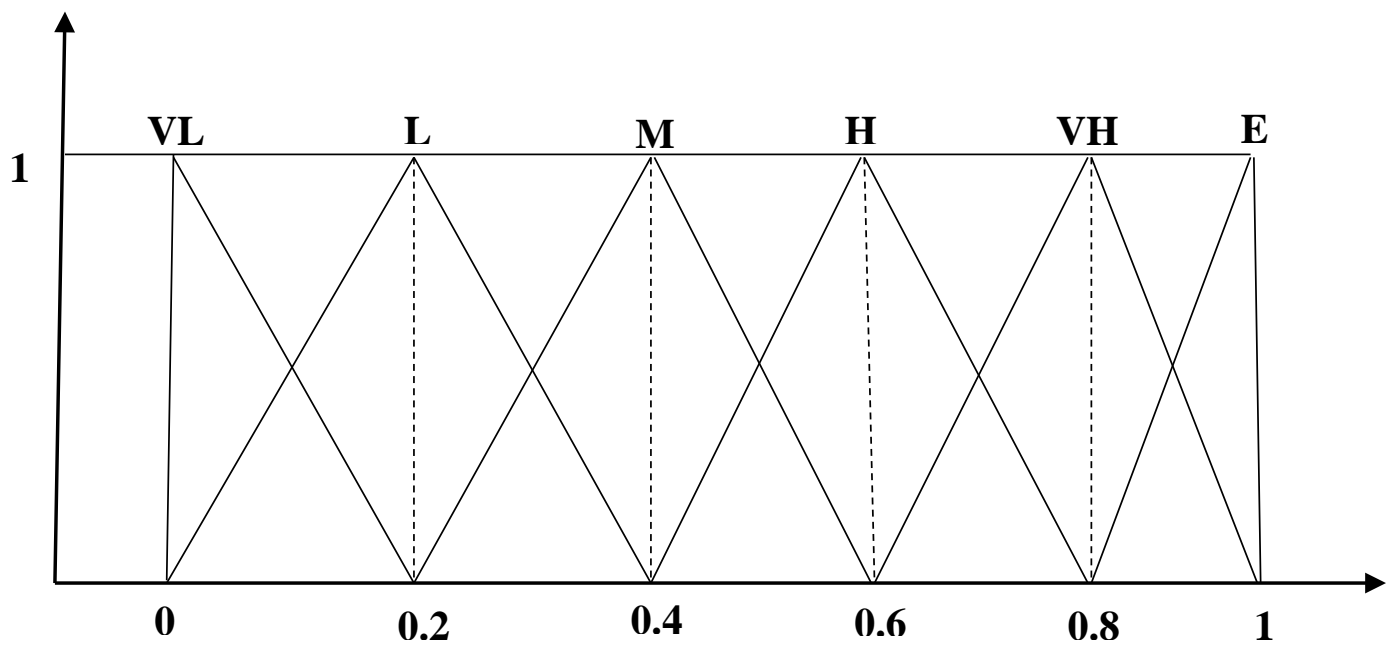

Fig. 2:- Membership function of linguistic values

Table 2:- Linguistic terms and triangular fuzzy numbers

\begin{tabular}{|lc|}
\hline Linguistic terms & Fuzzy numbers \\
\hline Very low (VL) & $(0,0,0.2)$ \\
Low (L) & $(0,0.2,0.4)$ \\
Medium (M) & $(0.2,0.4,0.6)$ \\
High $(\mathrm{H})$ & $(0.4,0.6,0.8)$ \\
Very high (VH) & $(0.6,0.8,1)$ \\
Excellent $(\mathrm{E})$ & $(0.8,1,1)$ \\
\hline
\end{tabular}

Identification of criteria for green supplier selection:-

Six various criteria are to be considered for green supplier selection. The expert team selected six different criterion for supplier selection and evaluation. These six criteria are defined as: cost (C1), quality (C2), service (C3), green product (C4), pollution control (C5), and environment management (C6).

Table 3:- Green supplier selection criterion and its definition.

\begin{tabular}{|ll|}
\hline Criteria & Definition \\
\hline Cost & It is considered most important criteria in supplier selection. It involves \\
\hline
\end{tabular}




\begin{tabular}{|ll|}
\hline Quality. & $\begin{array}{l}\text { purchasing cost, transportation, energy, inspection, security, holding cost. } \\
\text { Total quality management is important part of organization during production } \\
\text { process. Quality function means, minimize rejection rate and produce quality } \\
\text { and environmental friendly goods. }\end{array}$ \\
Service & $\begin{array}{l}\text { Service includes to provide quality product at low price, delivery reliability, and } \\
\text { warrants claims. } \\
\text { In recent years, there is green competency between suppliers. It is valuable and } \\
\text { highly favorable for organization. It also includes green packaging. The purpose } \\
\text { of green packaging is to protect environment by using environmental friendly } \\
\text { raw material. Green packaging is also called 4RID. It stands for: reduce, reuse, } \\
\text { reclaim, recycle, and degradable. }\end{array}$ \\
It is important parameter for green supplier selection process. Companies want to \\
deal only those supplier that can help to minimize solid wastes. \\
Pollution control \\
Environment management.
\end{tabular}

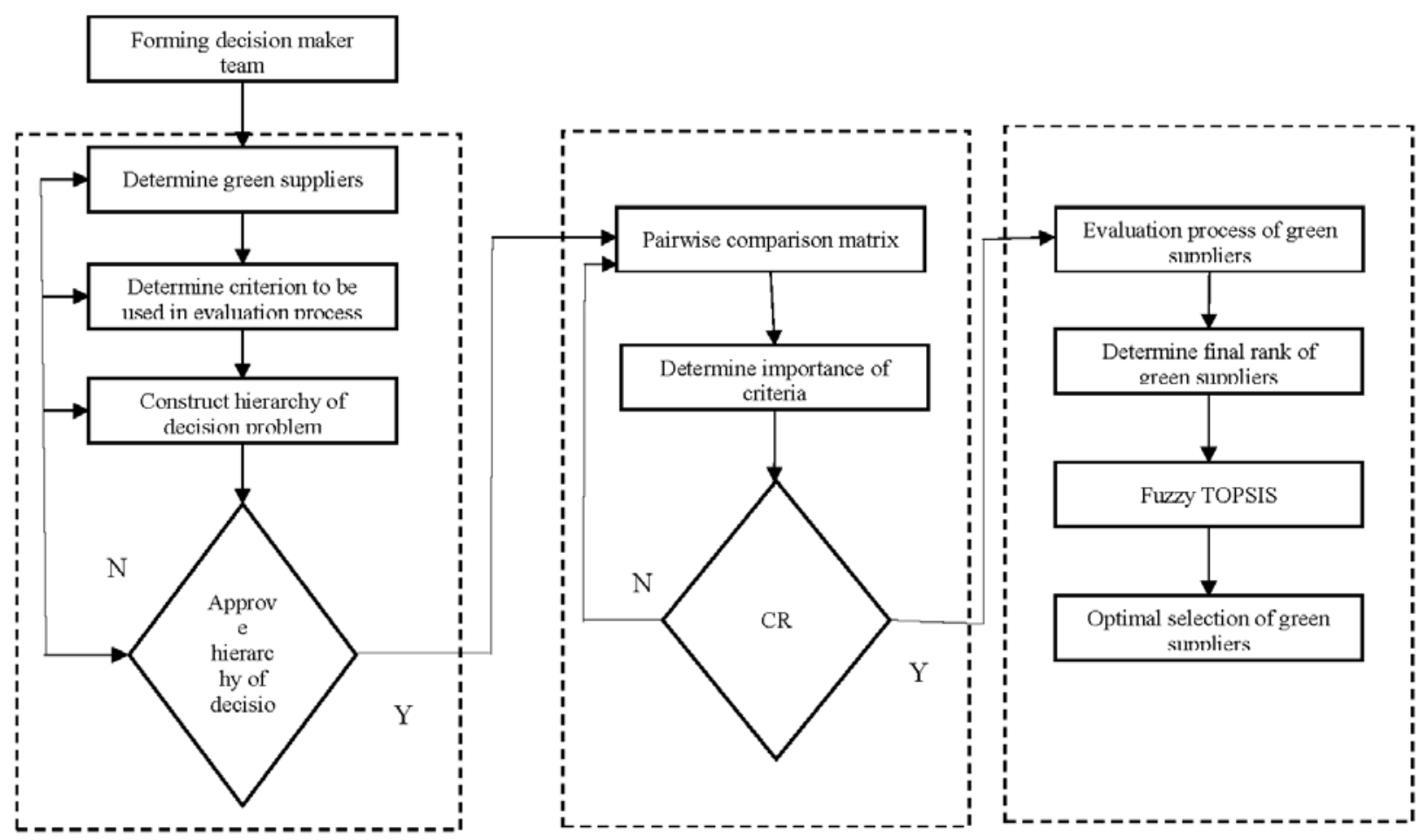

Fig.3:- Proposed model for green supplier selection. 


\section{Weights of criteria:-}

After developing hierarchical structure of decision problem, the weights of criteria is used in evaluation procedure and calculated with the help of AHP method. In this stage, the decision maker in expert team are given the task to determine individual pairwise comparison matrix by utilizing the scale given in (Table 1).

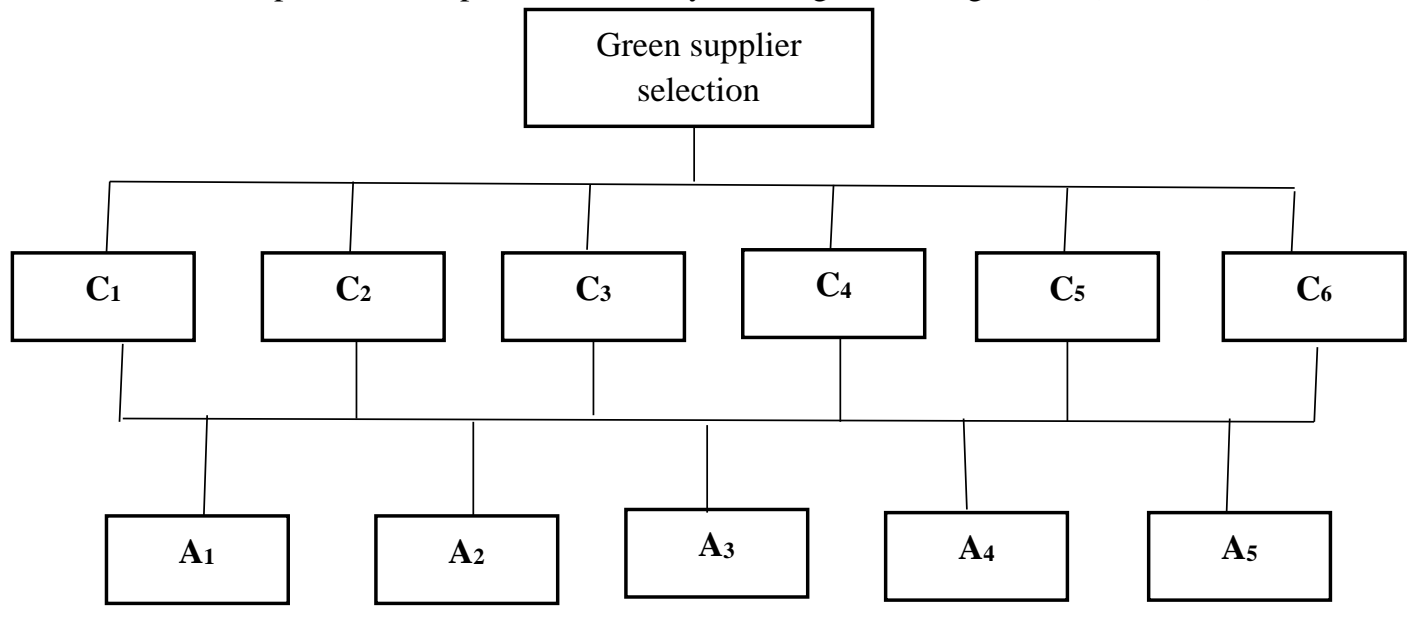

Fig. 4:- The decision hierarchy of green supplier selection

Table 4:- The pairwise comparison matrix

\begin{tabular}{|lllllll|}
\hline & C1 & C2 & C3 & C4 & C5 & C6 \\
\hline C1 & 1 & 1 & 1 & 3 & 3 & 5 \\
C2 & 1 & 1 & 1 & 2 & 3 & 3 \\
C3 & 1 & 1 & 1 & 1 & 1 & 2 \\
C4 & 0.33 & 0.50 & 1 & 1 & 3 & 5 \\
C5 & 0.33 & 0.33 & 1 & 0.33 & 1 & 2 \\
C6 & 0.20 & 0.33 & 0.50 & 0.20 & 0.50 & 1 \\
\hline
\end{tabular}

Table 5. Results obtained with AHP

\begin{tabular}{|llllll|}
\hline Criteria & W & $\lambda_{\max }$ & CI & RI & CR \\
\hline C1 & 0.226 & 6.332 & 0.0664 & 1.24 & 0.053 \\
C3 & 0.228 & & & & \\
C4 & 0.168 & & & & \\
C5 & 0.175 & & & & \\
C6 & 0.098 & & & & \\
\hline
\end{tabular}

After applying AHP method, the results of pairwise comparison matrix are given in Table 4. The C1, C2, and C4 are most important criterion in the green supplier selection process by AHP. The consistency ratio of pairwise comparison matrix is computed as $0.053<0.1$. The weights are presented to be consistent. These weights are used in selection process.

\section{Evaluation of alternatives and determine the final rank:-}

In this stage, fuzzy evaluation matrix is built for evaluation of suppliers (alternatives) by using linguistic variables in Table 2. Fuzzy evaluation matrix is presented in Table 6. Linguistic variables are in upper section of Table 6, lower section is composed of triangular fuzzy numbers which are equivalent of linguistic variables.

The second step is to determine fuzzy weighted decision table. Using criteria weights computed by AHP (Table 5). In this phase, the weighted evaluation matrix is constructed by using Eq. (12). The computed results of fuzzy weighted decision matrix are shown in Table 7. As shown in Table 7, that element $\tilde{V}_{i j}, \forall_{i} j$ are normalized positive triangular fuzzy number and their ranges belong to [0, 1]. Thus, fuzzy positive-ideal solution (FPIS, $\left.A^{*}\right)$ and fuzzy negative-ideal solution $\left(F N I S, A^{-}\right)$as $\tilde{V}_{i}^{*}=(1,1,1)$ and $\tilde{V}_{i}^{-}=(0,0,0)$ for benefit criterion, and $\tilde{V}_{i}^{*}=(0,0,0)$ 
and $\tilde{V}_{i}^{-}=(1,1,1)$ for cost criterion. In the third step, the distance of each alternative from $D^{*}$ and $D^{-}$can be obtained by using Eq. (15) and Eq. (16). In the fourth step, the similarities to an ideal solution is calculated by using Eq. (17) (Yang \& Hung, 2007).

Table 6:- Fuzzy evaluation matrix for green supplier (alternative)

\begin{tabular}{|lllllll|}
\hline & \multicolumn{1}{c}{ C1 } & \multicolumn{1}{c}{ C2 } & C3 & C4 & C5 & C6 \\
\hline A1 & $(0,0.2,0.4)$ & $(0.8,1,1)$ & $(0.2,0.4,0.6)$ & $(0.4,0.6,0.8)$ & $(0,0,0.2)$ & $(0.6,0.8,1)$ \\
A2 & $(0.2,0.4,0.6)$ & $(0.2,0.4,0.6)(0,0,0.2)$ & $(0,0.2,0.4)$ & $(0,0.2,0.4)(0,0,0.2)$ \\
A3 & $(0,0,0.2)$ & $(0,0,0.2)$ & $(0.4,0.6,0.8)$ & $(0.2,0.4,0.6)$ & $(0.2,0.4,0.6)(0,0.2,0.4)$ \\
A4 & $(0.4,0.6,0.8)$ & $(0,0.2,0.4)$ & $(0,0.2,0.4)$ & $(0.8,1,1)$ & $(0,0.2,0.4)$ & $(0.2,0.4,0.6)$ \\
A5 & $(0,0.2,0.4)$ & $(0.2,0.4,0.6)(0.6,0.8,1)$ & $(0,0,0.2)$ & $(0.2,0.4,0.6)(0.2,0.4,0.6)$ \\
W & 0.226 & 0.228 & 0.168 & 0.175 & 0.098 & 0.055 \\
\hline
\end{tabular}

Table 7:- Weighted evaluation for green supplier selection

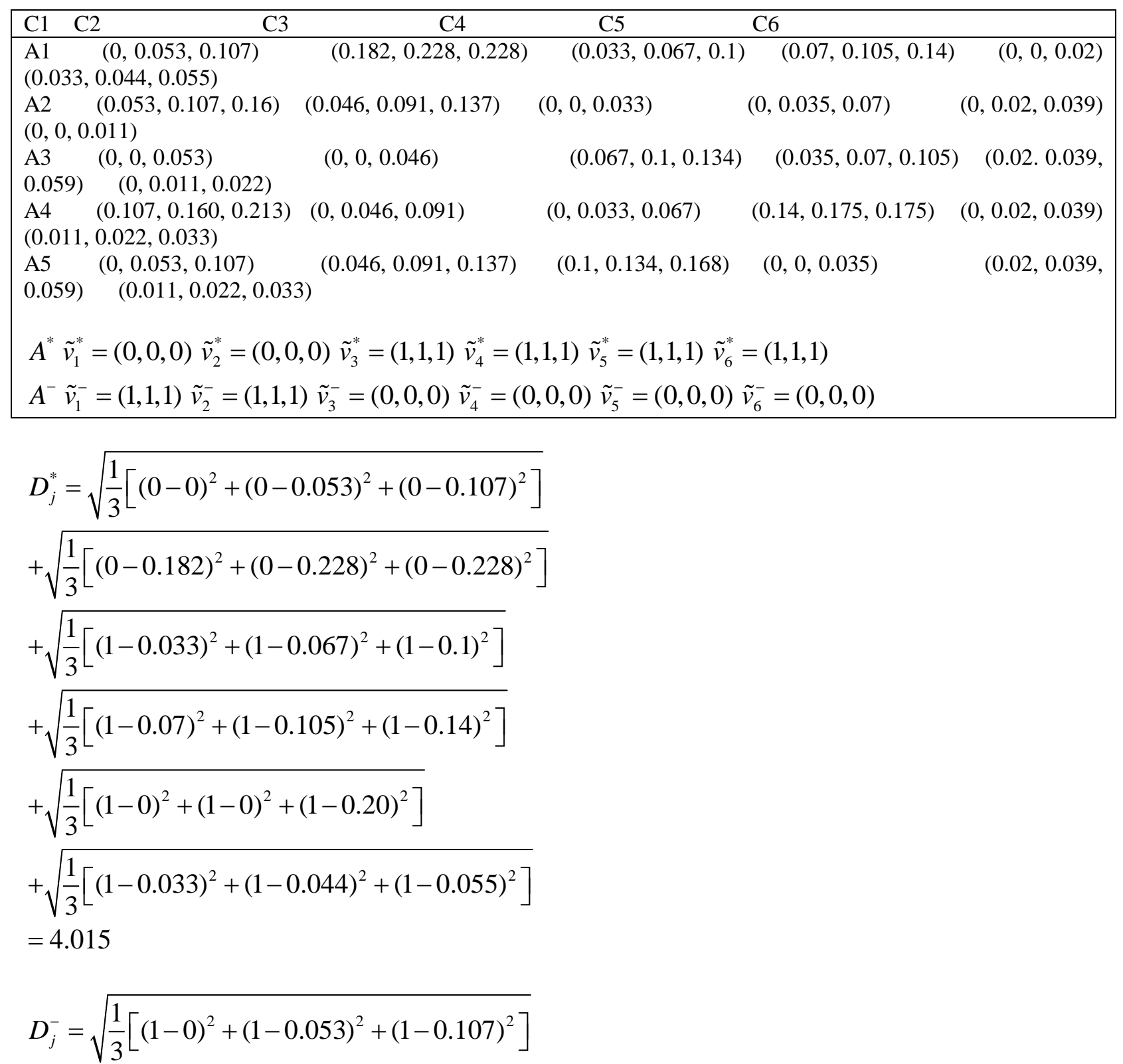




$$
\begin{aligned}
& +\sqrt{\frac{1}{3}\left[(1-0.182)^{2}+(1-0.228)^{2}+(1-0.228)^{2}\right]} \\
& +\sqrt{\frac{1}{3}\left[(0-0.033)^{2}+(0-0.067)^{2}+(0-0.1)^{2}\right]} \\
& +\sqrt{\frac{1}{3}\left[(0-0.07)^{2}+(0-0.105)^{2}+(0-0.14)^{2}\right]} \\
& +\sqrt{\frac{1}{3}\left[(0-0)^{2}+(0-0)^{2}+(0-0.20)^{2}\right]} \\
& +\sqrt{\frac{1}{3}\left[(0-0.033)^{2}+(0-0.044)^{2}+(0-0.020)^{2}\right]} \\
& =1.972 \\
& C_{j}=\frac{D_{j}^{-}}{D_{j}^{*}-D_{j}^{-}}=\frac{1.972}{4.015+1.972}=0.329
\end{aligned}
$$

Table 8:- Fuzzy TOPSIS results

\begin{tabular}{|llllc|}
\hline Alternatives & $D_{j}^{*}$ & $D_{j}^{-}$ & $C C_{j}$ & Rank \\
\hline A1 & 4.015 & 1.972 & 0.329 & A4 \\
A2 & 4.145 & 1.913 & 0.316 & A5 \\
A3 & 3.838 & 2.225 & 0.367 & A1 \\
A4 & 3.987 & 2.078 & 0.343 & A2 \\
A5 & 3.970 & 1.999 & 0.335 & A3 \\
\hline
\end{tabular}

The table 8 , shows value of each alternative with ranking. Therefore, the final ranking of each alternative is: $A_{4}>A_{5}>A_{1}>A_{2}>A_{3}$.

\section{Conclusion:-}

Green supplier selection is a critical and multi-criteria decision making process that incorporates impression and vagueness of decision makers. In order to develop sustainable development, companies need to emphasize on green production and protect environment. An efficient green supplier selection methods helps to lessen environmental and legal risks and enhance competitiveness in the market. In this paper, a model establishes to choose decision criteria for evaluation and measure performance of green supplier under fuzzy environment. The AHP method is used first to develop hierarchical structure of decision criteria and determine priority weight vector of all criterion. The results of decision criteria are applied next to fuzzy TOPSIS method to select most suitable supplier.

\section{References:-}

1. Amy. Lee et al, H.-Y. K.-F.-C. (2009). A green supplier selection model for high-tech industry. Expert Systems with Applications, 36(4), 7917-7927.

2. Badri, M. A. (2001). A combined AHP-GP model for quality control systems. International Journal of Production Economics, 72(1), 27-40.

3. C. A. Weber et al, J. R. (1991). Vendor selection criteria and methods. European Journal of Operational Research, 50(1), 2-18.

4. Chang, Y.-H., \& Wang, S.-Y. (2007). A survey and optimization-based evaluation of development strategies for the air cargo industry. International Journal of Production Economics, 106(2), 550-562.

5. Chen, C.-T. (2000). Extensions of the TOPSIS for group decision-making under fuzzy environment. Fuzzy Sets and Systems, 114(1), 1-9.

6. Dickson, G. W. (1966). An analysis of vendor selection systems and decisions. Journal of Purchasing, 2(1), 517. 
7. Ghodsypour, S., \& O'Brien, C. (1998). A decision support system for supplier selection using an integrated analytic hierarchy process and linear programming. International Journal of Production Economics, 56-57, 199-212.

8. He-Yau Kang et al, C.-F. H.-C. (2009). A green supplier selection model for high-tech industry. Expert Systems with Applications, 36(4), 7917-7927.

9. Hwang, C.-L., \& Lai, Y.-J. (1993). A new approach for multiple objective decision making. Computers \& Operations Research, 20(8), 889-899.

10. Noci, G. (1997). Designing 'green' vendor rating systems for the assessment of a supplier's environmental performance. European Journal of Purchasing \& Supply Management, 3(2), 103-114.

11. Önüt, S., \& Soner, S. (2007). Transshipment site selection using the AHP and TOPSIS approaches under fuzzy environment. Waste Management, 28(9), 1552-1559.

12. R. M Grisi et al, L. G. (2010). Supplier performance evaluation for green supply chain management. Business Performance Measurement and Management, 149-163.

13. Rao, P. (2006). Greening of Suppliers/In-bound Logistics. In the South East Asian Context.

14. Saaty, T. L. (1980). The analytic hierarchy process. New York: McGraw-Hill.

15. Thoo Ai Chin et al, H. H. (2015). Green Supply Chain Management, Environmental Collaboration and sustainability Performance. 12th Global Conference on Sustainable Manufacturing, 26, 695-699.

16. Wang, J.-J., \& Yang, D.-L. (2007). Using a hybrid multi-criteria decision aid method for information systems outsourcing. Computers \& Operations Research, 34(12), 3691-3700.

17. Yan, G. (2009). Research on green suppliers' evaluation based on AHP \& genetic algorithm. International Conference on Signal Processing Systems, IEEE, 615-619.

18. Yang, T., \& Hung, C.-C. (2007). Multiple-attribute decision making methods for plant layout design problem. Robotics and Computer-Integrated Manufacturing, 23(1), 126-137.

19. Yuzhong, Y., \& Liyun, W. (2007). Grey entropy method for green supplier selection. International conference on WiCom, IEEE, 4682-4685.

20. Zadeh. (1975). The concept of a linguistic variable and its application to approximate reasoning-I. Information Sciences, 8(3), 199-249.

21. Zadeh, L. (1965). Fuzzy sets. Information and Control, 8(3), 338-353. 